\title{
A Serological Study on Incidence of Brucellosis in Sheep in Ludhiana District of Punjab State of India
}

\author{
Neharika Saxena*, B.B. Singh, J.P.S. Gill and R.S. Aulakh \\ School of Public Health and Zoonoses, Guru Angad Dev Veterinary and Animal Sciences \\ University, Ludhiana-141004, India \\ *Corresponding author
}

\section{A B S T R A C T}

\begin{tabular}{|l|}
\hline Key w or d s \\
Brucellosis, \\
Prevalence, \\
Agglutination, \\
Sheep, Sero- \\
Epidemiology. \\
\hline Article Info \\
\hline Accepted: \\
28 August 2017 \\
Available Online: \\
10 September 2017 \\
\hline \hline
\end{tabular}

We investigated the prevalence of Brucellosis in sheep in Ludhiana district of Punjab state of India. Serum samples of sheep $(n=171)$ from slaughter houses and an organized farm were analyzed with common sero diagnostic tests RBPT, STAT, MAT and ELISA. Out of 171 sera, 31 were positive by one or more of the four tests; 12 were positive and 140 were negative by all the four tests. The prevalence was $10.52 \%$ by RBPT and ELISA. The mean anti-Brucella antibody titers were $41.53+18.69$ by STAT and $52.30+32.03$ by MAT. ELISA gave maximum true positives and RBPT gave minimum of false negative results. RBPT showed the highest sensitivity (78.26\%) followed by ELISA (75\%), STAT (68\%) and MAT (50\%), respectively. STAT had the highest specificity (98.63\%) followed by ELISA (96.79\%), RBPT and MAT (95.89\% each), respectively. STAT had the highest positive predictive value of $89.47 \%$ followed by ELISA (79.26\%), RBPT (75\%) and MAT (66.67\%), respectively. RBPT had the highest negative predictive value of $96.55 \%$ followed by ELISA $(96.18 \%)$, STAT $(94.74 \%)$ and MAT $(92.11 \%)$, respectively. STAT had the highest positive likelihood ratio of 49.64 while MAT gave the highest negative likelihood ratio of 0.52 .

\section{Introduction}

Brucellosis is an important zoonotic disease that causes huge economic losses to the livestock farmers and is of public health significance. It causes abortions, placentitis, epididymitis, orchitis and reproductive losses in animals. The causative agents of Brucellosis in sheep are Brucella ovis and Brucella melitensis. Brucellosis is endemic in India and is prevalent in all parts of the country. In a study conducted in various districts of Punjab in 2000, the overall prevalence of Brucellosis was found to be $3.60 \%$ in goats (Gill et al., 2000). However, no such data is available on sheep.
The incidence of Brucellosis was reported to be $7 \%$ in sheep in Sangrur district of Punjab, India (Grewal and Kaur, 2000). But no information is available on the prevalence of the disease in sheep in other districts of Punjab.

The present study was undertaken to determine the seroprevalence of Brucellosis in sheep in Ludhiana district of Punjab state of India employing the common serodiagnostic methods - Rose Bengal Plate Test (RBPT), Standard Tube Agglutination Test (STAT), Microagglutination Test (MAT) and 
Competitive Enzyme Linked Immunosorbant Assay (cELISA).

\section{Materials and methods}

\section{Serum samples}

Blood samples were collected from adult sheep from slaughter houses in the city and an organized sheep farm located in a village near Ludhiana. Serum was separated from the clotted blood and stored at $-20^{\circ} \mathrm{C}$ till use.

\section{Seroepidemiological studies}

All the serum samples from sheep were subjected to analysis with four common serodiagnostic techniques - RBPT, STAT, MAT and cELISA.

\section{Rose Bengal Plate Agglutination Test (RBPT)}

RBPT was carried out by colored antigen with the method of Morgan et al., (1978). $10 \mu 1$ of antigen was mixed with $10 \mu 1$ of serum and observed for clump formation.

\section{Estimation of antibody titers by Standard Tube Agglutination Test (STAT)}

The standard method recommended by OIE (2009) was followed. Brucella abortus plain antigen (Punjab Veterinary Vaccine Institute, Ludhiana) was employed for the test. The highest serum dilution showing 50\% agglutination was taken as the end point for the titer of serum. A titer of 1:40 or above was considered positive.

\section{Estimation of antibody titers by Microtiter Agglutination Test (MAT)}

MAT was performed as per the standard method (Williams and Whittemore, 1971). The formation of matt signified agglutination while button formation was indicative of a negative reaction. Titers were recorded as the reciprocal of the highest dilution of the serum giving at least 50 percent agglutination.

\section{Competitive Enzyme Linked Immunosorbant Assay (cELISA)}

All the serum samples were subjected to analysis by competitive ELISA employing a commercial kit named Svanovir Brucella Antibody cELISA Kit (Svanova). The kit is based on a solid phase competitive ELISA. It is subjected to treatment with a monoclonal antibody $(\mathrm{mAb})$ for the o-polysaccharide portion of the S-LPS antigen. The sera are exposed to Brucella abortus smooth lipopolysaccaride (S-LPS) coated wells on microtiter plates.

If Brucella antibodies are present in the test sample they will bind to the antigens in the well and block these antigenic sites. If Brucella antibodies are absent in the sample, these sites will remain free and the monoclonal antibody which was added together with the sample will bind to these free antigenic sites. After an incubation period the unbound materials are removed by rinsing and a goat anti - mouse IgG conjugated with horseradish peroxidase (HRP) is added to the plate. The HRP conjugate will bind to the specific $\mathrm{mAb}$ in absence of Brucella antibodies in the sample. Unbound materials are removed by rinsing prior to the addition of the substrate. Development of a blue color shows negative result. The reaction is stopped by addition of stop solution; the color changes to yellow. The result is read at $450 \mathrm{~nm}$.

The samples were run in duplicates. The optical density (OD) of the controls and samples was measured at $450 \mathrm{~nm}$ with photometer. After 15 minutes OD was measured after the addition of Stop Solution to prevent fluctuation in OD values. 


\section{Calculations}

The mean OD values were calculated for each of the controls and samples.

The percent inhibition (PI) values were calculated using the following formula:

$\mathrm{PI}=\frac{100-(O D \text { samples or control } \times 100)}{O D \text { conjugate control }}$

\section{Results and Discussion}

\section{Seroepidemiology of brucellosis in sheep}

This study was aimed to find out the prevalence of Brucellosis in sheep in Ludhiana district of Punjab state of India using RBPT, STAT, MAT and C-ELISA.

A total of 171 serum samples from sheep were analyzed for Brucellosis by RBPT, STAT, MAT and ELISA. Out of 171, a total of 31 sera were found to be positive for Brucellosis by one or more of the four serological techniques employed (Table 1). A total of 140 samples were found to be negative by all the four methods. ELISA detected the highest number of positive samples - 25, followed by RBPT, STAT and MAT - 20 each, respectively (Fig. 1). Several samples were positive by more than one test. Eighteen samples were positive by both RBPT and ELISA while 12 samples were positive by all the four serological tests. It is apparent from the above results that ELISA detected more positive samples followed by RBPT, STAT and MAT.

The mean titers of anti - Brucella antibodies in sheep sera were $41.53+18.69$ by STAT and $52.30+32.03$ by MAT, respectively (Table 2). The difference between the two values was significant $(\mathrm{P}<0.05 \%)$.

Prevalence of the disease in sheep was estimated to be $10.52 \%$ by RBPT and ELISA.
The highest number of true positive results were yielded by ELISA $(11.11 \%)$, followed by RBPT $(10.52 \%)$, STAT $(9.94 \%)$ and MAT (7.01\%).

The highest number of true negative results were obtained by STAT (84.21\%) followed by RBPT \&MAT $(81.87 \%)$ each and ELISA (77.19\%), respectively. Maximum false positive results were obtained by RBPT, MAT \& ELISA (3.50\%) followed by STAT $(1.16 \%)$

Highest number of false negative results were obtained with MAT (7.01\%), followed by STAT (4.67\%), ELISA (3.50\%) and RBPT $(2.92 \%)$.

It appears from the above results that ELISA detected more of the true positives, while STAT gave the best identification of true negative samples. STAT yielded the least number of false positives results while RBPT gave the minimum of false negative results.

RBPT was found to have the highest sensitivity $(78.26 \%)$ followed by ELISA $(75 \%)$, STAT (68\%) and MAT $(50 \%)$, respectively. STAT had the highest specificity (98.63\%) followed by ELISA (96.79\%), RBPT and MAT (95.89\% each), respectively.

The prevalence of the disease was estimated to be $14.62 \%$ by STAT, $14.12 \%$ by MAT, $13.61 \%$ by RBPT and $13.33 \%$ by ELISA respectively.

STAT was found to have the highest positive predictive value of $89.47 \%$ followed by ELISA (79.26\%), RBPT (75\%) and MAT (66.67\%) respectively. RBPT was found to have the highest negative predictive value of 96.55\% followed by ELISA (96.18\%), STAT $(94.74 \%)$ and MAT $(92.11 \%)$, respectively. STAT had the highest positive likelihood ratio of 49.64 while MAT gave the highest negative likelihood ratio of 0.52 (Table 3 ). 
Table.1 Sheep sera positive by RBPT, STAT, MAT or ELISA

\begin{tabular}{|c|c|c|c|c|c|}
\hline S. no. & Sample & RBPT & STAT & MAT & ELISA \\
\hline 1 & s019 & Weak+ve & -ve & -ve & -ve \\
\hline 2 & sh027 & \begin{tabular}{|l|} 
Weak+ve \\
\end{tabular} & -ve & -ve & -ve \\
\hline 3 & sh 05 & Weak+ve & -ve & -ve & -ve \\
\hline 4 & sh 034 & +ve & $+v e$ & $+v e$ & $+v e$ \\
\hline 5 & sh SA & strong +ve & $+v e$ & $+v e$ & $+v e$ \\
\hline 6 & sh 021 & Weak+ve & -ve & -ve & -ve \\
\hline 7 & sh 01 & $+v e$ & +ve & +ve & +ve \\
\hline 8 & SB10 & strong + ve & +ve & +ve & +ve \\
\hline 9 & S 23 & -ve & -ve & +ve & -ve \\
\hline 10 & Sh049 & $+v e$ & +ve & +ve & +ve \\
\hline 11 & SBS 1,60 & $+v e$ & $+v e$ & +ve & $+v e$ \\
\hline 12 & S 9 & -ve & -ve & -ve & $+v e$ \\
\hline 13 & $\mathrm{~S} 02$ & -ve & +ve & +ve & -ve \\
\hline 14 & S15 & -ve & -ve & $+v e$ & +ve \\
\hline 15 & S 64 & +ve & -ve & +ve & +ve \\
\hline 16 & $\mathrm{Sx} 27$ & +ve & +ve & +ve & +ve \\
\hline 17 & Sx 48s & $+v e$ & $+v e$ & -ve & +ve \\
\hline 18 & Sx 90s & $+v e$ & +ve & -ve & +ve \\
\hline 19 & Sx 87s & +ve & $+v e$ & + ve & $+v e$ \\
\hline 20 & Sx 15 & $+v e$ & $+v e$ & +ve & $+v e$ \\
\hline 21 & Sx 33 & +ve & +ve & -ve & +ve \\
\hline 22 & Sx 49s & Weak+ve & -ve & -ve & -ve \\
\hline 23 & Sx 46s & $+v e$ & $+v e$ & -ve & $+v e$ \\
\hline 24 & Sx 36 & +ve & -ve & -ve & -ve \\
\hline 25 & Sx 2s & +ve & -ve & -ve & -ve \\
\hline 26 & SR1 90 & $+v e$ & -ve & -ve & +ve \\
\hline 27 & SR1 8 & +ve & $+v e$ & +ve & $+v e$ \\
\hline 28 & su 97M & -ve & -ve & -ve & +ve \\
\hline 29 & su $94 \mathrm{M}$ & $+v e$ & +ve & +ve & $+v e$ \\
\hline 30 & su $87 \mathrm{M}$ & -ve & +ve & +ve & +ve \\
\hline 31 & su $89 \mathrm{~F}$ & -ve & -ve & -ve & +ve \\
\hline 32 & su $79 \mathrm{~F}$ & -ve & -ve & -ve & $+v e$ \\
\hline 33 & su 95M & -ve & -ve & +ve & -ve \\
\hline 34 & su $83 \mathrm{~F}$ & -ve & +ve & +ve & -ve \\
\hline 35 & $\mathrm{Su} 85 \mathrm{~F}$ & -ve & +ve & +ve & -ve \\
\hline 36 & $\mathrm{~S} 1$ & +ve & +ve & +ve & +ve \\
\hline
\end{tabular}


Table.2 Comparison of STAT and MAT titers of anti-Brucella antibodies in sheep

\begin{tabular}{|l|l|c|c|}
\hline \multicolumn{3}{|c|}{ Titer (I. U.) } \\
\hline S. no. & Animal no. & STAT & MAT \\
\hline 1 & SR1(8) & 40 & 40 \\
\hline 2 & Sh 01 & 40 & 40 \\
\hline 3 & Sh 034 & 40 & 40 \\
\hline 4 & Sh SA & 40 & 80 \\
\hline 5 & Sh 049 & 40 & 40 \\
\hline 6 & S02 & 40 & 80 \\
\hline 7 & S1 & 40 & 80 \\
\hline 8 & SB-10 & 40 & 80 \\
\hline 9 & Su 83 F & 40 & 40 \\
\hline 10 & Su 85 F & 40 & 80 \\
\hline 11 & Su 87 M & 40 & 40 \\
\hline 12 & Su 94 M & 80 & 80 \\
\hline 13 & Sx 46 s & 40 & 20 \\
\hline 14 & Sx 33 & 40 & 20 \\
\hline 15 & Sx 15 & 40 & 40 \\
\hline 16 & Sx 87 s & 80 & 80 \\
\hline 17 & Sx 90 s & 40 & 20 \\
\hline 18 & Sx 48 s & 40 & 20 \\
\hline 19 & Sx 27 & 80 & 80 \\
\hline 20 & SBS 1,60 & 80 & 160 \\
\hline 21 & Sh 05 & 20 & 20 \\
\hline 22 & S64 & 20 & 40 \\
\hline 23 & S23 & 20 & 40 \\
\hline 24 & S15 & 20 & 40 \\
\hline 25 & Su 92 F & 20 & 20 \\
\hline 26 & Su 95 M & 20 & 40 \\
\hline Mean \pm SD & $\mathbf{4 1 . 5 3 \pm 1 8 . 6 9}$ & $\mathbf{5 2 . 3 0} \mathbf{3 2 3}$ \\
\hline 175 & & \\
\hline
\end{tabular}

The difference is significant $(\mathrm{p}<0.05)$.

Table.3 Sensitivity and specificity of agglutination tests compared to C-ELISA

\begin{tabular}{|l|l|l|l|}
\hline \multicolumn{4}{|c|}{ Prevalence of Brucellosis in Sheep } \\
\hline Values & RBPT & STAT & MAT \\
\hline True Positive & 18 & 17 & 15 \\
\hline False Positive & 8 & 1 & 5 \\
\hline False Negatives & 6 & 7 & 9 \\
\hline True Negatives & 140 & 144 & 143 \\
\hline Sensitivity & $75.00 \%$ & $70.83 \%$ & $62.50 \%$ \\
\hline Specificity & $94.59 \%$ & $99.31 \%$ & $96.62 \%$ \\
\hline Positive Likelihood Ratio & 13.88 & 102.71 & 18.50 \\
\hline Negative Likelihood Ratio & 0.26 & 0.29 & 0.39 \\
\hline Disease Prevalence & $13.95 \%$ & $14.20 \%$ & $13.95 \%$ \\
\hline Positive Predictive Value & $69.23 \%$ & $94.44 \%$ & $75.00 \%$ \\
\hline
\end{tabular}


The results of our study indicate that ovine Brucellosis is a major problem of concern in Ludhiana district of Punjab state of India. Based on the serologic analyses of 171 serum samples of sheep, the prevalence of Brucellosis in sheep in and around Ludhiana was found to be $10.52 \%$ by RBPT and ELISA.

Brucellosis is endemic in India and is prevalent in all parts of the country. In a national survey conducted on Brucellosis from 10 states (Isloor et al., 1998), the cumulative incidence in sheep was $7.9 \%$. This survey indicated widespread prevalence of Brucellosis in small domestic ruminants in the country.

Several serological surveys of small ruminant Brucellosis have indicated varying levels of infection in different states. In sheep, incidence of $4.9 \%$ in Karnataka (Desai et al., 1995), $11 \%$ in Delhi, 50\% in Punjab, 33\% in Rajasthan (Kumar et al., 1997), and $4.7 \%$ in Uttar Pradesh (Singh et al., 2000) have been reported earlier. Serological evidence of $B$. ovis infection in 6 out of 102 rams has been reported in the state of Himachal Pradesh (Katoch et al., 1996). A study was conducted on seroprevalence of Brucellosis in sheep from both organized and unorganized sectors of Kashmir valley by RBPT and STAT and the prevalence of Brucellosis was recorded.

About $6.50 \%$ prevalence of this disease was reported in sheep (Lone, 2013). In another study (Suryavanshi et al., 2014) in Maharashtra an overall prevalence of $17.68 \%$ was reported in sheep. In a study in Gujarat state the prevalence in sheep was found to be $8.80 \%$ by I-ELISA, $11.30 \%$ by RBPT and $11.10 \%$ by STAT (Sadhu et al., 2015).

The present study revealed the prevalence of Brucellosis in sheep in Ludhiana district of Punjab to be $10.52 \%$ by RBPT and ELISA.

\section{Acknowledgement}

The authors are deeply thankful to Dr. H M Saxena (Professor, Department of Veterinary Microbiology, GADVASU) for his kind help and support.

\section{Conflict of interest}

The authors declare that there is no conflict of interest.

\section{References}

Desai, T., Krishnappa, G and Upadhyaye AS 1995. Incidence of Brucellosis in sheep, goats and some human risk groups. Mysore J. Agri. Sci. 29: 348-351.

Gill, J.P.S., Kaur, S; Joshi, DV and Sharma J K 2000. Proceedings of the 9th International Symposium on Veterinary Epidemiology and Economics, Punjab Agricultural University, Ludhiana.

Grewal, S.S., and Kaur S 2000. Survey of sheep and goat Brucellosis in Sangrur district (Punjab, India). J. Parasitol. Appl. Anim. Biol. 9(2): 67-74.

Isloor, S., Renukaradhya, GJ and Rajashekhar M 1998. Brucellosis research. In Annual Report (1997-1998) of AICRP on Animal Disease Monitoring and Surveillance. Bangalore, India 13-18.

Katoch, R.C., Joshi, VB; Sharma, M; Batta, MK and Nagal KB 1996. Seroprevalence of Brucella ovis, Brucella melitensis and Chlamydia psittaci in rams. Ind. J. Anim. Sci. 66(11): 1130-1131.

Kumar, P.K., Singh, DK and Barbuddhe SB 1997. Serological evidence of Brucellosis in sheep and goats. Ind. J. Anim. Sci. 67(3): 180-182.

Lone, I.M., Baba, MA; Shah, MM; Iqbal, A and Sakina A 2013. Seroprevalence of Brucellosis in sheep of organized and unorganized sector of Kashmir valley. 
Vet. World 6: 530-533.

Morgan, W.J., Mackinnon, DT; Gill, KPW; Gower, SGM and Norris, PIW 1978. Brucellosis Diagnosis: Standard Laboratory Techniques Report Series no. 1, Weybridge, England.

OIE. 2009. Bovine Brucellosis, Section 2.4.3. Manual of the Diagnostic Tests and Vaccines for Terrestrial Animals, vol. $1 ., 5^{\text {th }}$ edition Office International Des Epizooties, Paris, France, pp. 624-59.

Sadhu, D.B., Panchasara, HH; Chauhan, HC; Sutariya, DR; Parmar, VL and Prajapati, HB 2015. Seroprevalence and comparison of different serological tests for Brucellosis detection in small ruminants. Vet. World 8(5): 561-566.

Singh, S.V., Aggarwal, GS; Batra, HV; Gupta, VK and Singh N 2000. Monitoring of Brucella infection associated with reproductive losses using multiple serological tests in organized goat and sheep flocks. Ind. J. Anim. Sci. 70(2): 154-156.

Suryavanshi, S.N., Tembhurne, PA; Gohain, $S$ and Ingle VC 2014. Prevalence of Brucella antibodies in sheep and goats in Maharashtra. Ind. Res. J. Extn. Edu. 14(4) (Special Issue): 75-77.

Williams, J.E., and Whittemore, AD 1971. Serological diagnosis of pullorum disease with the micro agglutination system. Appl. Microbiol. 21: 392-399.

\section{How to cite this article:}

Neharika Saxena, B.B. Singh, J.P.S. Gill and Aulakh, R.S. 2017. A Serological Study on Incidence of Brucellosis in Sheep in Ludhiana District of Punjab State of India. Int.J.Curr.Microbiol.App.Sci. 6(9): 3066-3072. doi: https://doi.org/10.20546/ijcmas.2017.609.377 